\title{
Clinical impact of recent genetic discoveries in osteoporosis
}

This article was published in the following Dove Press journal:

The Application of Clinical Genetics

3 October 2013

Number of times this article has been viewed

\section{Braxton D Mitchell \\ Elizabeth A Streeten}

Department of Medicine and Program for Personalized and Genomic Medicine, University of Maryland School of Medicine, and Geriatric Research and Education Clinical Center, Veterans Administration Medical Center, Baltimore, MD, USA
Correspondence: Braxton D Mitchell University of Maryland School of Medicine, 685 W Baltimore St, MSTF 302, Baltimore, MD 2I20I, USA Tel + I 410706016I

Email bmitchel@medicine.umaryland.edu
Abstract: Osteoporotic fracture carries an enormous public health burden in terms of mortality and morbidity. Current approaches to identify individuals at high risk for fracture are based on assessment of bone mineral density and presence of other osteoporosis risk factors. Bone mineral density and susceptibility to osteoporotic fractures are highly heritable, and over 60 loci have been robustly associated with one or both traits through genome-wide association studies carried out over the past 7 years. In this review, we discuss opportunities and challenges for incorporating these genetic discoveries into strategies to prevent osteoporotic fracture and translating new insights obtained from these discoveries into development of new therapeutic targets.

Keywords: bone mineral density, genome-wide association studies, osteoporosis, prediction, fracture, genetics

\section{Introduction}

Osteoporosis is a major public health problem that is associated with significant mortality and morbidity. Although osteoporosis is often regarded as a disorder of women, and indeed women are disproportionately affected, the disorder also carries an enormous health burden in men. An estimated $20 \%$ of women and $4 \%$ of men in the US were diagnosed with osteoporosis in 2005-2006, with rates increasing to $48 \%$ in women and $12 \%$ in men over the age of 85 years. ${ }^{1}$ It has further been estimated that up to one half of all women and one quarter to one third of all men over the age of 50 years will experience a hip fracture during their lifetime. ${ }^{2}$ The economic impact is enormous, with an estimated health care cost of $\$ 17$ billion in direct costs in the US alone. ${ }^{3}$

Osteoporosis is a systemic skeletal disorder characterized by microarchitectural deterioration in bone tissue that results in reduced bone strength, bone fragility, and increased susceptibility to fracture. ${ }^{4}$ The most common fracture sites are the hip and spine, although any bone can be affected. Identifying individuals with low bone strength and high risk for fracture is important so that strategies to slow bone loss, including pharmacotherapy, can be deployed. Although the molecular basis underlying these defects and the triggers that initiate them are not completely understood, a strong familial contribution to bone mineral density (BMD) is well established, with genes estimated to contribute $60 \%-80 \%$ of the variability in BMD. ${ }^{5,6}$ It is hoped that current efforts aimed at identifying the specific genes involved will provide further insight into the molecular basis underlying osteoporosis and will eventually lead to new therapeutic targets and prevention strategies.

The goal of this review is to summarize the current knowledge of factors contributing to increased fracture risk in osteoporosis, with an emphasis on genetic factors, and 
to discuss the potential impact of new genetic discoveries on identifying individuals at risk for osteoporotic fracture and preventing future fractures.

\section{Development and sequelae of osteoporosis}

Bone is a dynamic tissue that is continually being formed and resorbed during one's lifetime. Bone mass at any time of life is the integral of the amount of bone accrued during growth and consolidation (peak bone mass) and the loss of bone that occurs with aging. The importance of achieving an optimal level of bone mass in early adulthood has highlighted the role of early nutritional and lifestyle factors in bone health, and led some to characterize osteoporosis as a pediatric disease, ${ }^{7}$ or at least an adult disease with its seeds in childhood.

There is substantial variability both in the acquisition of peak bone mass, attained during early adulthood (by women in the early 20 s and by men in the mid 20 s), and in the rate of bone loss that begins during the perimenopausal years. In both men and women, peak bone mass is generally maintained in the 30 s and early 40 s, with a slow loss of bone mass that accelerates in women during the menopause. Both peak mass and rate of bone loss contribute to fracture risk; that is, the fracture risk will be high in individuals who achieved a low peak bone mass even if the subsequent rate of bone loss is small, as well as in individuals who achieve a relatively high peak bone mass but who experience a relatively high rate of bone loss in their later years. In a given year, about $10 \%$ of the skeleton is broken down and reformed by bone remodeling. ${ }^{8}$

Bone remodeling occurs at numerous focal areas throughout the skeleton. The net amount of bone formation and resorption can be crudely assessed by bone turnover markers that are routinely measured in many laboratories. Bone formation markers, which are protein products of the osteoblast, include bone-specific alkaline phosphatase, procollagen-1 amino peptide, and osteocalcin, while resorption markers include C-telopeptide and N-telopeptide, which are breakdown products of collagen (the main protein in bone).

Osteoporosis is associated with increased morbidity and mortality. In the first 6 months following hip fracture, there is an excess mortality of at least $18 \% .^{9}$ A meta-analysis showed that mortality 1 year after hip fracture was more than twice as high in men as in women. ${ }^{10}$ Although men are younger than women at the time of hip fracture, they fare worse than women following hip fracture due to greater comorbidity and higher postoperative infection rates (reviewed by Sterling ${ }^{11}$ ). Increased mortality also follows vertebral compression fracture. ${ }^{12}$
In addition to increased mortality, osteoporotic fracture is frequently followed by chronic pain, functional limitation, and psychologic difficulties, that include fear of falling and social isolation. ${ }^{13}$ Overall quality of life is reduced in both women ${ }^{14}$ and men $^{15}$ following osteoporotic fracture. Medical treatment of osteoporosis reduces fracture risk and enhances quality of life, ${ }^{16}$ and some medications have been associated with improved overall survival. ${ }^{17}$

\section{Diagnosis, risk estimation, and treatment}

Bone strength is determined by two factors, ie, BMD and bone quality. ${ }^{18} \mathrm{BMD}$ is determined by dual energy X-ray absorptiometry (DXA) and is usually performed at the lumbar spine and hip. Bone quality can be assessed by threedimensional imaging modalities, such as peripheral computed tomography and high resolution magnetic resonance imaging, ${ }^{19}$ although these are currently used primarily in research settings and are not available clinically. The assessment of fracture risk using only BMD has limitations.

In postmenopausal women and men over the age of 50 years, the diagnosis of osteoporosis can be made either by the occurrence of a fragility fracture (following a fall from standing height, after ruling out malignancy) or by a DXA T-score of $\leq-2.5$ at the lumbar spine, total hip, or femoral neck (Table 1). This T-score threshold corresponds to a BMD that is 2.5 standard deviation $(\mathrm{SD})$ units or more lower than the BMD for an "average" young adult female. The World Health Organization has published guidelines further classifying a T-score $\geq-1.0$ as normal and a T-score of -1.0 to -2.5 in the absence of fracture as "low bone mass" (or osteopenia). ${ }^{20}$ The definition of osteoporosis in premenopausal women and men younger than 50 years is

Table I Diagnosis of osteoporosis

\begin{tabular}{lll}
\hline & $\begin{array}{l}\text { Postmenopausal } \mathbf{W} \\
\text { and } \mathbf{M}>\mathbf{5 0} \text { years }\end{array}$ & $\begin{array}{l}\text { Premenopausal } \mathbf{W} \\
\text { and } \mathbf{M}<\mathbf{5 0} \text { years }\end{array}$ \\
\hline Osteoporosis & $\begin{array}{l}\text { T-score } \leq-2.5 \text { or } \\
\text { fragility fracture }\end{array}$ & $\begin{array}{l}\text { Z-score } \leq-2.0 \text { and } \\
\text { fragility fracture }\end{array}$ \\
Low bone mass & -1.0 to -2.5, & - \\
(osteopenia) & no fracture & Z-score $<-2.0$ and \\
Low bone mass & - & no fracture \\
for age & & Z-score $\geq-2.0$, no \\
Normal & T-score $\geq-1.0$, & fracture
\end{tabular}

Note: Adapted from: World Health Organization. Assessment of fracture risk and its application to screening for postmenopausal osteoporosis. Report of a WHO Study Group. World Health Organ Tech Rep Ser. 1994;843:I-12920 and MartinezMorillo M, Grados D, Holgado S. Premenopausal osteoporosis: how to treat? Reumatol Clin. 2012;8:93-97. ${ }^{21}$

Abbreviations: W, women; $\mathrm{M}$, men. 
controversial, but most agree that the patient must have experienced a fragility fracture and have a $\mathrm{BMD} \leq 2 \mathrm{SD}$ that of the average BMD for individuals of the same age and gender (ie, a Z-score $\leq-2.0$ ). ${ }^{21}$

Pharmacologic treatment to prevent fracture is currently targeted to those at high risk of fracture. According to guidelines established by the US National Osteoporosis Foundation, postmenopausal women and men older than 50 years and with osteoporosis (fracture or T-score $\leq-2.5$ at the spine or femoral neck) should be treated. ${ }^{22}$ Current pharmacotherapies to prevent osteoporotic fracture are designed to slow bone loss. A number of different drugs are available, most of which act as antiresorptive agents on osteoclasts to decrease bone loss, although there is currently one that acts by stimulating bone formation (teriparatide). There is a wide variation among patients in response to drugs, both in terms of efficacy and frequency/type of adverse reactions. ${ }^{23,24}$

Because of the high prevalence of osteoporosis and the proven benefit of pharmacologic treatment in reducing fractures, ${ }^{25}$ there is a strong incentive to identify individuals at risk for future fracture. DXA is the most widely used tool for this purpose, although there are concerns that DXA utilization rates have dropped since 2007, coincident with a lowering of Medicare reimbursement rates for non-facility-based DXAs. ${ }^{26-28}$ Nevertheless, in a large meta-analysis involving approximately 90,000 years of follow-up and over 2,000 fractures, it was estimated that each SD decrease in BMD from the age-adjusted mean was associated with a 2.3-fold increase in incidence of vertebral fractures and a 2.6-fold increase in hip fractures. The predictive ability was roughly similar to (or, for hip or spine measurements, better than) that of a one SD increase in blood pressure for stroke and better than a one SD increase in serum cholesterol concentration for cardiovascular disease..$^{29}$ In a later meta-analysis, Johnell et al reported that each SD decrease in BMD corresponded approximately to a 2.9-fold increase in hip fracture risk. ${ }^{30}$

While these results illustrate the utility of DXA as a screening tool, DXA does not have a high sensitivity at the individual level for fracture prediction. ${ }^{31,32}$ Indeed, while the lifetime risk of fracture in women and men over age 50 years is estimated to be $50 \%$ and $30 \%$, respectively, ${ }^{2}$ more than $50 \%$ of women and $70 \%$ of men who experienced a fracture did not meet DXA criteria for osteoporosis. ${ }^{33}$ Tools that assess bone quality (eg, high resolution peripheral computed tomography) improve fracture risk prediction over DXA but are not available clinically. ${ }^{34}$ To improve fracture prediction, the FRAX ${ }^{\circledR}$ tool (http://www.shef.ac.uk/FRAX/) was developed in 2008 by the World Health Organization as an online calculator that integrates information from BMD and clinical risk factors to calculate the 10-year probability of hip fracture and the 10 -year probability of any major osteoporotic fracture (clinical spine, forearm, hip, or shoulder fracture). The clinical risk factors included in FRAX fracture prediction include age, gender, height, weight, prior fracture, parental history of hip fracture, current glucocorticoid use, current smoking, excess alcohol intake, rheumatoid arthritis, and secondary causes of osteoporosis. Separate prediction equations have been developed for different geographic regions and ethnic groups. The National Osteoporosis Foundation guidelines recommend pharmacologic treatment of those with low bone mass who have a 10-year risk of fracture of at least $20 \%$ for any fracture or $3 \%$ for hip fracture as calculated by FRAX. ${ }^{22}$ Using these treatment guidelines, approximately $30 \%$ of women and $19 \%$ of men over age 50 years in the US meet the criteria for pharmacologic treatment. ${ }^{35}$

\section{Risk factors for osteoporotic fracture}

Because of the wide availability of DXA, the high precision with which it can be measured, and the correlation of BMD with fracture risk, much of the research into the determinants of osteoporotic fracture has focused on identifying the risk factors associated with variability in BMD. We provide below and in Table 2 a brief summary of risk factors for $\mathrm{BMD}$ and fracture; more extensive reviews on this subject have been published elsewhere. ${ }^{36-38}$

BMD is lower and hip fracture rates are higher in women compared with men and in populations of Caucasian origin compared with non-Caucasian populations. Higher body weight is also consistently associated with higher BMD and lower hip fracture risk, a correlation that may be attributable to multiple factors, including higher mechanical loading on skeletal bone that may promote mineralization and bone strength, skeletoprotective effects of adipokine secretion from fat tissue, and cushioning that may protect bone from the trauma of falls. Most non-vertebral fractures are associated with falls, and this dependence on falls complicates the ability to predict fractures accurately.

Reproductive and hormonal factors play an important role in regulating bone metabolism, with bone loss accelerating in women at the onset of menopause. Bone sites most affected by estrogen deficiency are those with high trabecular content, such as the spine and ultradistal forearm. ${ }^{36}$ Estradiol is the most important hormone for bone health in both genders, but other hormones are important, including growth hormone, testosterone, and insulin. Nutritional factors, including calcium, 
Table 2 Non-genetic risk factors for osteoporosis

\begin{tabular}{|c|c|c|}
\hline Personal factors & Medications & Diseases \\
\hline Caucasian & Glucocorticoids & Monogenic diseases \\
\hline Female & Anticoagulants (warfarin, heparin) & OI, OPPG \\
\hline Age $>50$ years & Antiepileptics & Muscular dystrophy \\
\hline Low body weight & $\begin{array}{l}\text { Sex hormone suppressants } \\
\text { (eg, aromatase inhibitors, Depo-Provera }{ }^{\circledR} \text { ) }\end{array}$ & $\begin{array}{l}\text { Connective tissue disorders (eg, Marfan syndrome, } \\
\text { Ehlers-Danlos syndrome) }\end{array}$ \\
\hline Physical inactivity & Proton pump inhibitors & Cystic fibrosis \\
\hline Falls & Thiazolidinediones & Metabolic (eg, glycogen storage diseases) \\
\hline Muscle weakness & Antidepressants & Complex diseases \\
\hline Reduced vision & & Renal (chronic kidney disease, hypercalciuria) \\
\hline Smoking & & Rheumatoid arthritis \\
\hline Excess alcohol & & Hematologic (eg, mastocytosis) \\
\hline \multirow[t]{3}{*}{ Elevated homocysteine (females only) } & & $\begin{array}{l}\text { Gastrointestinal (inflammatory bowel disease, } \\
\text { celiac disease) }\end{array}$ \\
\hline & & Pulmonary (chronic obstructive pulmonary disease) \\
\hline & & $\begin{array}{l}\text { Endocrine (types I and } 2 \text { diabetes mellitus, } \\
\text { hyperthyroidism, hyperparathyroidism) }\end{array}$ \\
\hline
\end{tabular}

Abbreviations: OI, osteogenesis imperfecta; OPPG, osteogenesis imperfecta ocular form.

vitamin $\mathrm{D}$, and protein intake, play an important role in both the acquisition of peak bone mass and its maintenance in later life. However, a more precise understanding of the role of nutritional factors on BMD and bone health has been hampered by methodologic limitations in assessing dietary intakes and the time lag between dietary intake and its effects on bone health.

Other important risk factors for osteoporosis and reduced BMD include physical inactivity (which may increase fracture risk in part by reducing muscle mass) cigarette smoking, alcohol use, low sun exposure (for production of vitamin D), and use of some medications, including glucocorticoids and anticonvulsants. The impact of some of these osteoporosis risk factors differs slightly according to age and across sites, perhaps due in part to differing compositions of cortical versus trabecular bone. ${ }^{39}$ Recent studies have also indicated that hip geometry contributes to fracture risk. ${ }^{40,41}$

\section{Recent studies of genetic factors associated with osteoporosis}

There is a strong genetic contribution to susceptibility to osteoporosis, with genes estimated to account for about $25 \%$ of the variance in liability to osteoporotic fractures, ${ }^{42} 25 \%-54 \%$ for fractures of the wrist, ${ }^{43,44}$ and up to $48 \%$ for fractures of the hip. ${ }^{42}$ Despite these moderate to high heritabilities, the fracture phenotype is a very challenging one for use in genetic studies because fracture risk is influenced by a number of diverse physiologic factors, including BMD and age-related declines in bone microarchitecture and quality, muscle strength, balance, cognition, cardiovascular function, and vitamin D status. Since each of these factors is itself under at least partial genetic control, variants that influence fracture susceptibility entirely through any of these other factors should be more easily detectable in an analysis of the factor itself, rather than fracture.

Because of its wide use and acceptability as a screening tool, numerous genetic studies have been carried out on BMD, providing highly consistent estimates that genes account for $60 \%-80 \%$ of the total variability in BMD. ${ }^{5}$ That low BMD is a significant mechanism through which fracture risk can be transmitted through families was demonstrated by Seeman et al over 20 years ago, who showed that BMD in the lumbar spine and femoral neck was lower in the daughters of women with osteoporotic fractures than in the daughters of non-osteoporotic women. ${ }^{45}$ Significant heritabilities of BMD in young adulthood and premenopausal adults have been reported, ${ }^{46-48}$ implying a genetic contribution to the acquisition of peak bone mass. It is also presumed that genes contribute significantly to variability in aging-related bone loss, and in fact a few small studies have reported moderate heritabilities of bone loss. ${ }^{46,49-52}$ However, precise estimates of the genetic contribution to bone loss are lacking because of the difficulty in assessing bone change reliably, ie, specific trajectories of bone change are non-linear and highly agedependent, making it critical that multiple measurements over time be obtained in a standardized fashion..$^{53}$ These difficulties notwithstanding, it would be immensely valuable to identify bone change-related genes because many may fall in pathways that are more amenable to therapeutic modification than pathways specific for bone acquisition.

Early efforts to identify specific genes related to variation in BMD and fracture risk focused on identifying biologically motivated candidate genes and testing specific genotyped variants for association with BMD (or fracture). While many 
positive association results were published, with few exceptions (eg, the estrogen receptor 1 [ERI gene] and low-density lipoprotein receptor-related proteins 4 and 5 [LRP4, LRP5] genes), most initially reported associations turned out to be difficult to replicate. With advances in genomic technology, numerous genome-wide association studies (GWAS) of BMD and related traits have been published over the last 6-7 years. It is important to appreciate that the GWAS approach is designed to test the hypothesis of association with genetic variants that are common in the population, ie, typically variants with minor allele frequencies of $5 \%$ or greater. Although the variants (typically single nucleotide polymorphisms [SNPs]) included on GWAS arrays are generally neutral (ie, do not have functional effects), they may be highly correlated with numerous other surrounding SNPs, including some that may influence gene expression or function. The largest of the BMD GWAS studies published to date was from the Genetic Factors of Osteoporosis Consortium and included a discovery sample of over 32,000 subjects from 17 different populations and an independent replication sample of over 50,000 subjects. ${ }^{54}$ In this study, 56 loci significantly associated with BMD, of which 14 were found to associate also with fracture. Several additional BMD-associated loci have since been identified, some from non-Caucasian populations, bringing the total number of BMD-associated loci to $62 .{ }^{55}$ The loci that have been robustly associated with BMD through GWAS studies to date are listed in Table 3. The effect sizes of these loci are uniformly small, each accounting for far less than $1 \%$ of the total variation in $\mathrm{BMD}$; even collectively, all identified loci account for less than $6 \%$ of the total variation in femoral neck BMD. ${ }^{54}$ Future GWAS studies including even more subjects will undoubtedly be published, through which even more BMD-associated loci will be identified. However, these newly associated loci will almost certainly have even smaller effect sizes than those already discovered.

One goal of GWAS is to obtain insights into disease pathogenesis by determining whether the associated loci map to any novel molecular pathways. Many of the 62 associated loci do indeed map to genes that fall within pathways related to bone biology, such as the $\mathrm{Wnt} / \beta$-catenin signaling pathway, the RANK-RANKL-osteoprotegerin (OPG) pathway, mesenchymal stem cell differentiation, and endochondral ossification, although the involvement of these pathways in osteoporosis pathophysiology had generally been known before the advent of GWAS. The Wnt/ $\beta$-catenin signaling pathway, which is mediated by interactions of Wnt proteins with their receptors, causes an accumulation of $\beta$-catenin in the cytoplasm that then translocates into the nucleus where it participates in gene transcription. The importance of this pathway in bone health was first recognized with the discovery of a mutation in LRP5 as the cause of osteoporosis pseudoglioma syndrome, ${ }^{56}$ and it is now appreciated that this pathway is crucially important for a variety of processes, including bone cell differentiation, proliferation, and apoptosis. The RANK-RANKL-OPG pathway is an important regulator of bone resorption that involves receptor activator of nuclear factor-KB (RANK), its ligand (RANKL), and OPG, a socalled decoy receptor of RANKL. RANK is expressed by osteoclasts and their precursors, RANKL is expressed on osteoblast surfaces, and OPG is produced by osteoblasts. It is the binding of RANKL to its receptor, RANK, that controls the differentiation, proliferation, and survival of osteoclasts. Figure 1 illustrates how the Wnt and RANK/RANKL/OPG pathways interact with each other to regulate the balance between bone formation and resorption.

The process of mesenchymal stem cell differentiation is highly relevant to bone turnover because mesenchymal stem cells are multipotent stromal cells that can differentiate into a variety of cell types, including osteoblasts, chondrocytes, and adipocytes. The endochondral ossification pathway involves processes active during fetal development of the mammalian skeleton. A fuller description of the Wnt, RANK-RANKLOPG, and endochondral ossification pathways is beyond the scope of this review, but excellent reviews are available on these subjects. ${ }^{57}$

Finding genes for fracture risk is likely to be more difficult than for BMD due to the much smaller sample sizes generally available for studies of fracture and the complexity of the fracture phenotype. As previously noted, it is difficult enough to identify genes/SNPs associated with intermediate traits. For example, although over 60 SNPs have now been associated with BMD, for which the heritability is very high, the effect sizes of all are very small, and enormous sample sizes were required to identify these. Of the 16 SNPs that have been associated with fracture to date (see Table 3 ), most were tested because of their initial association with BMD, ${ }^{54,55}$ and all have odds ratios for fracture of 1.11 or lower for the risk allele with the exception of one, ie, rs13182402 in ALDH7A1 (odds ratio 2.25). This SNP was identified in a GWAS of fractures in a Chinese population..$^{58}$ ALDH7A1 is a gene in the aldehyde dehydrogenase 7 family (member A1) that degrades and detoxifies acetaldehyde, which inhibits osteoblast proliferation and results in decreased bone formation. ${ }^{59}$ For further reading, the reader is referred to several of the numerous excellent reviews that have been published recently on the genetics of BMD and hip fracture. ${ }^{60-63}$ 
Table 3 Loci associated with bone mineral density at the hip or spine at genome-wide levels of significance

\begin{tabular}{|c|c|c|c|c|}
\hline Pathway & Closest candidate gene & Locus & $\begin{array}{l}\text { Lead single nucleotide } \\
\text { polymorphism }\end{array}$ & $\begin{array}{l}\text { Also associated with } \\
\text { osteoporotic fracture?* }\end{array}$ \\
\hline \multirow[t]{12}{*}{ Wnt } & AXINI & $|6 p| 3.3$ & rs9921222 & \\
\hline & CTNNBI & $3 p 22.1$ & rs430727 & $Y$ \\
\hline & ERCI/WNT5B & $|2 p| 3.33$ & rs288757l & \\
\hline & $J A G I$ & $20 \mathrm{p} / 2.2$ & rs3790160 & \\
\hline & LRP5 & ||$q \mid 3.2$ & rs3736228 & $\mathrm{Y}$ \\
\hline & MBL2/DKKI & $10 q 21.1$ & rsI373004 & $\mathrm{Y}$ \\
\hline & MEF2C & $5 q \mid 4.3$ & rsI366594 & \\
\hline & RSPO3 & $6 q 22.32$ & rs|3204965 & \\
\hline & SOST & $|7 q 21.3|$ & rs4792909 & $\mathrm{Y}$ \\
\hline & WLS & $|\mathrm{p} 3| .3$ & rs 12407028 & \\
\hline & WNTI GIFAM3C & $7 q 31.31$ & rs380I387 & $\mathrm{Y}$ \\
\hline & WNT4 & $1 \mathrm{p} 36.12$ & rs7521902 & $\mathrm{Y}$ \\
\hline \multirow[t]{3}{*}{ RANK-RANKL-OPG } & OPG (TNFRSFI IB) & $8 q 24.12$ & rs2062377 & \\
\hline & RANK (TNFRSFIIA) & $18 q 21.33$ & rs884205 & \\
\hline & RANKL (TNFRSFII) & $13 q \mid 4$ & rs9533090 & \\
\hline \multirow[t]{6}{*}{ Endochondrial ossification } & CDKAI/SOX4 & $6 p 22.3$ & rs9466056 & \\
\hline & MEPE/SPPI/IBSP & $4 q 21.1$ & rs6532023 & Y \\
\hline & sox6 & IIp|5.2 & rs7108738 & \\
\hline & sox9 & $17 q 24.3$ & rs7217932 & \\
\hline & SP7 & $12 q 13.13$ & rs2016266 & \\
\hline & SUPT3HIRUNX2 & $6 p 21.1$ & rsll755II64 & \\
\hline \multirow[t]{32}{*}{ Other } & $A B C F 2$ & $7 q 36.1$ & rs78I 2088 & \\
\hline & ADAMTSI 8 & $16 q 23$ & rsII864477 & \\
\hline & AKAPII & $13 q|4.1|$ & rs9533090 & \\
\hline & ALDH7AI & $5 q 31$ & rs|3|82402 & $Y$ \\
\hline & ANAPCI & $2 q 13$ & rsI7040773 & \\
\hline & ARHGAPI & ||$p|| .2$ & rs7932354 & \\
\hline & $\mathrm{Cl} 2 \mathrm{orf23}$ & $12 q 23.3$ & rsI05305I & \\
\hline & Cl6orf38/CLCN7 & $16 p \mid 3$ & rsI3336428 & \\
\hline & CI8ORFI9/FAM2IOA & $|8 p| 1.21$ & rs4796995 & $Y$ \\
\hline & C6ORF97IESRI & $6 q 25.1$ & rs4869742 & \\
\hline & C7orf58 & $7 q 31$ & rs 13245690 & \\
\hline & CPNI & $10 q 24.2$ & rs7084921 & \\
\hline & CRHRI & $17 q 12$ & rs930352I & \\
\hline & CYLD & $16 q \mid 2.1$ & rsI56498I & \\
\hline & $\mathrm{DHH}$ & $12 q 13.12$ & rs 12821008 & \\
\hline & DNM3 & Iq24.3 & rs479336 & \\
\hline & FAM9B/KALI & Xp22.31 & rs5934507 & \\
\hline & FLJ42280/SHFMI & $7 \mathrm{q} 21.3$ & rs778I370 & \\
\hline & FOXLI/FOXC2 & 16q24.1 & rsl0048I46 & \\
\hline & FUBP3 & $9 q 34.11$ & rs785I693 & $\mathrm{Y}$ \\
\hline & GALNT3 & $2 q 24.3$ & rsI346004 & \\
\hline & GPATCHI & $19 q 13.11$ & rs10416218 & \\
\hline & HDAC5 & $|7 q 2|$ & rs228769 & \\
\hline & HOXC6 & $12 q 13.13$ & rs736825 & \\
\hline & IDUA & $4 p 16.3$ & rs3755955 & \\
\hline & INSIGZ & $2 q \mid 4.2$ & rsl878526 & \\
\hline & KCNMAI & 10q22.3 & rs707|206 & \\
\hline & KIAA20I8 & $3 q 13.2$ & rsl026364 & \\
\hline & KLHDC5/PTHLH & $|2 p| \mid .22$ & rs7953528 & \\
\hline & LEKRI & $3 q 25.31$ & rs34408I & \\
\hline & LIN7CIDCDC5 & ||$p|4|$. & rs 10835187 & $Y$ \\
\hline & MARK3 & $14 q 32.32$ & rsII623869 & \\
\hline
\end{tabular}

(Continued) 
Table 3 (Continued)

\begin{tabular}{|c|c|c|c|c|}
\hline Pathway & Closest candidate gene & Locus & $\begin{array}{l}\text { Lead single nucleotide } \\
\text { polymorphism }\end{array}$ & $\begin{array}{l}\text { Also associated with } \\
\text { osteoporotic fracture?* }\end{array}$ \\
\hline & MPP7 & $10 p \mid 1.23$ & rs3905706 & \\
\hline & NTANI & $16 p \mid 3.11$ & rs4985I55 & \\
\hline & PKDCC & $2 p 21$ & rs7584262 & \\
\hline & RPS6KA5 & $14 q 32.12$ & rs|286083 & Y \\
\hline & $S L C 25 A / 3$ & $7 q 21.3$ & rs4727338 & Y \\
\hline & SMG6 & $17 p \mid 3.3$ & rs479088I & \\
\hline & SPTBNI & $2 p 16.2$ & rs4233949 & $Y$ \\
\hline & STARD3NL & $7 p \mid 4.1$ & rs6959212 & Y \\
\hline & TXNDC3 & $7 p \mid 4.1$ & rs 10226308 & \\
\hline & XKR9/LACTB2 & $8 q \mid 3.3$ & rs70179|4 & \\
\hline & ZBTB40 & Ip36.12 & rs6426749 & $Y$ \\
\hline
\end{tabular}

Notes: *Associated with fracture at $P<0.001$. Table adapted from Richards et al ${ }^{55}$ and Estrada et al. ${ }^{54}$

Abbreviations: Wnt, wingless-related integration site; OPG, osteoprotegerin; RANK, receptor activator of nuclear factor-אB; RANKL, RANK ligand.

\section{Can genetic discoveries help to reduce the burden of osteoporotic fracture?}

The last 10 years has been an exciting time for osteoporosis genetics insofar as GWAS studies carried out during this time have led to the discovery of over 60 new loci robustly associated with variation in BMD, including some subsequently found to be associated with fracture. So how might these findings, or future discoveries coming down as even larger sample sizes become available, be translatable? Will knowledge gleaned from these discoveries improve our ability to predict individuals at risk for future fracture,

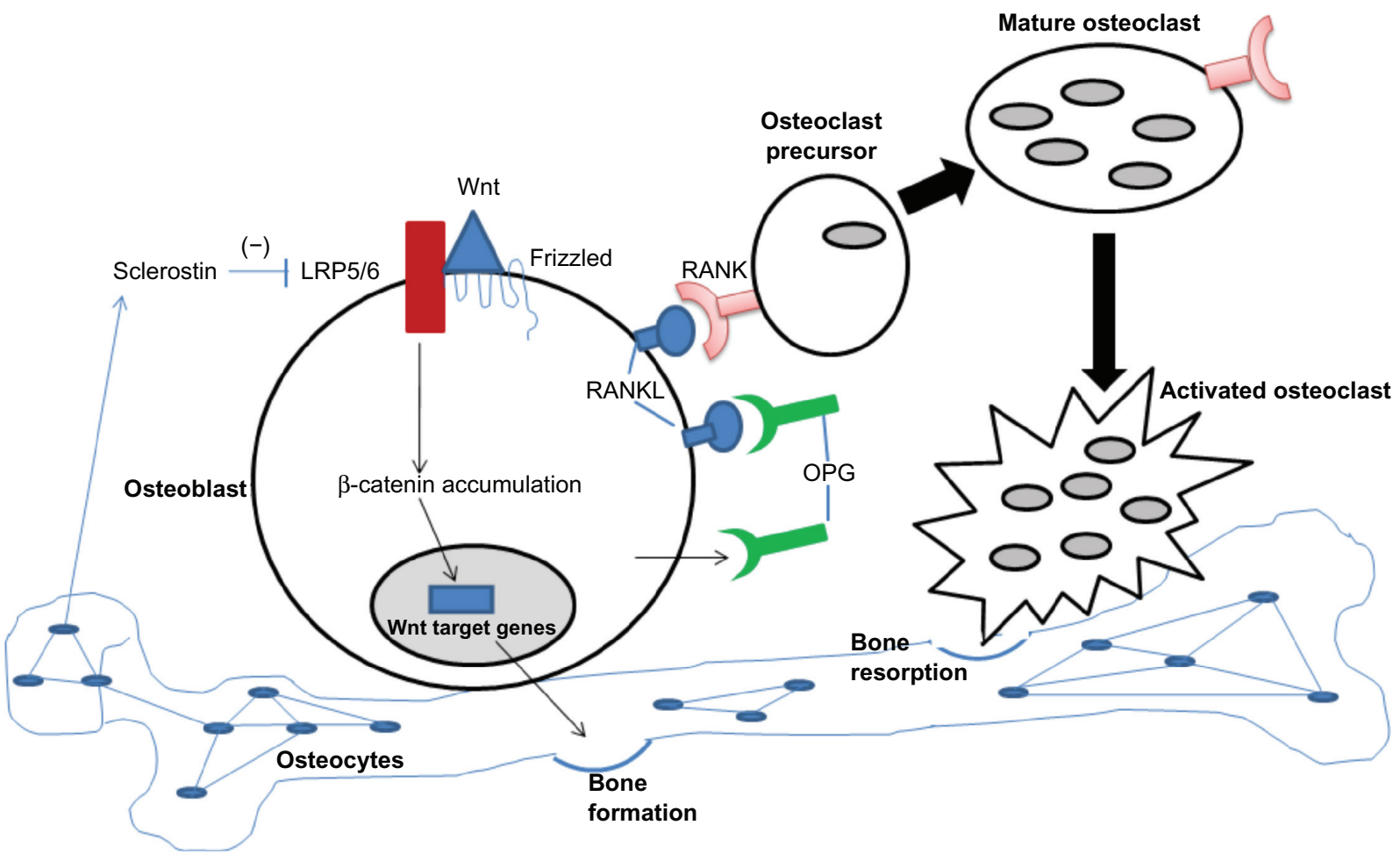

Figure I RANK/RANKL/OPG pathway in bone remodeling. The balance between bone formation and resorption is largely regulated by the Wnt pathway (bone formation), the RANK (pink symbols)/RANKL (blue symbols) pathway (osteoclast activation), and sclerostin (negative regulation of bone formation). Osteoblasts express the cell surface receptors RANKL and Wnt and also secrete a soluble decoy receptor, OPG (green symbols). Wnt protein binds coreceptors Fizzle-Fz and LRP5/6, leading to stabilization of $\beta$-catenin and its translocation to the nucleus to regulate target genes, resulting in increased bone formation. In the absence of OPG, RANKL on the osteoblast surface is available to bind RANK present on osteoclast precursors. Binding of RANK/RANKL leads to osteoclast maturation and resorption of bone. Sclerostin, secreted by osteocytes, inhibits Wnt from binding LRP5.

Abbreviations: RANK, receptor activator of nuclear factor-kappa B; RANKL, receptor activator of nuclear factor-kappa B ligand; OPG, osteoprotegerin; Wnt, winglessrelated integration site; LRP, low-density lipoprotein receptor protein. 
allowing initiation of early treatment? Will the discovered loci provide novel insights about bone biology and suggest new therapeutic targets? What new genetics/genomics approaches will be applied and what are the prospects for their translatability?

\section{Prediction}

There is good evidence that treating individuals who have already experienced a low trauma fracture, or who are osteoporotic by virtue of low BMD, with medications to either reduce bone resorption or increase bone formation can reduce the incidence of subsequent fractures. ${ }^{64}$ Unfortunately, about one-half of hip fractures occur in women without a a pre-existing fracture and who have a BMD that is not in the osteoporotic range, ${ }^{65}$ and prediction algorithms based on BMD and clinical information fractures (eg, DXA and FRAX) are imperfect for predicting individuals destined to experience a future fracture. An important question therefore is whether addition of genetic variants can improve prediction accuracy for fracture beyond that which can be determined by clinical risk factors alone.

Based on prospective studies, the discriminatory value of prognostic models based on clinical risk factors is moderate to good, with areas under the receiver operating characteristic curve ranging from 0.7 to $0.8 .^{66,67}$ Tran et al evaluated the improvement of these models for fracture prediction that would be achieved by adding into the model a variant in the collagen I alpha 1 (COL1A1) gene (rs1800012) that has been consistently associated with fracture risk (reviewed by Tran et al). ${ }^{68}$ This variant, which marks an Sp1 binding site in the first intron of COLIA1, has a minor allele frequency in Caucasians of approximately $19 \%$, and individuals homozygous for this variant have a 2-4-fold increased risk of fracture. Adding this variant to the hip fracture prediction model increased the area under the receiver operating curve only modestly from 0.86 to $0.88 .^{68}$ There was likewise only a very modest improvement in reclassification from normal to high risk. In the large Genetic Factors of Osteoporosis Consortium metaanalysis, a summary genotype score based on genotypes for all 62 BMD-associated loci had modest ability for prediction of osteoporosis (area under the receiver operating characteristic curve 0.59 ), but addition of this score to a model that included age and weight increased predictive discrimination only negligibly (from area under the receiver operating characteristic curve of 0.75 to 0.76$).{ }^{54}$ It should not be surprising that the marginal increase in discriminatory value achieved by adding genotypes at BMD-associated loci is minute given their small effect sizes. Moreover, one might expect variants associated with BMD to add very little predictive value to models that already include BMD as a clinical variable.

Although single variants have very small effect sizes and do not add to prediction, there is a theoretical benefit to considering multiple risk variants in aggregate in genetic profiling. One problem is that many of the known variants associated with fracture risk exert their effects through BMD, and thus their additional predictive value would be expected to be very marginal. The number of SNPs associated with fracture independently of BMD is very small. In simulation studies, Nguyen and Eisman estimated that 50 SNPs with odds ratios of $1.3-1.5$ would be needed to provide a significant increase in reclassification. ${ }^{69}$ However, given the complexity of the fracture phenotype, it seems unlikely that many associated SNPs will have effects this large. In fact, even in the absence of BMD screening, it seems unlikely at this point that SNPs will play a meaningful role in fracture prediction.

\section{Novel pathways}

A second area where genetic discoveries could potentially be translatable for osteoporosis lies in identifying new pathways that could serve as therapeutic targets. Despite the growing numbers of SNPs associated with BMD, few have led to major new insights about bone biology to date, largely because the genes marked by these SNPs have either fallen into pathways already known to be related to bone biology or the associated SNPs are either intergenic or appear to be correlated with genes having functions which are not clearly known. To make more sense of GWAS findings, more comprehensive analyses may be required that integrate additional information, such as tissue expression of implicated genes and functional annotation of identified SNPs and genes. In the large Genetic Factors of Osteoporosis Consortium meta-analysis, many of the identified SNPs mapped to genes in the RANK-RANKL-OPG, mesenchymal stem cell differentiation, and Wnt signaling pathways (see Estrada et $\mathrm{al}^{54}$ and Table 3). Integrating expression data to GWAS findings can prioritize the most biologically relevant candidate genes, as in the GWAS findings carried out by the Framingham Study ${ }^{70}$ and Genetic Factors of Osteoporosis Consortium. ${ }^{54}$ In an analysis of 180 SNPs associated with height in prior GWAS meta-analyses, Lui et al used rat, mouse, and human databases to identify genes expressed in growth plates to help localize the causal gene within many of the associated loci. ${ }^{71}$

One important application of new discoveries will be in the development of medications that more precisely target key 
mechanistic pathways, such as the RANK-ligand pathway, cathepsin $\mathrm{K}$ inhibition, and Wnt signaling manipulation. Identifying the key players in these pathways, especially the ones most amenable to targeting, represents an active area of ongoing research. ${ }^{72}$ For example, the antiresorptive agent, denosumab, is an antibody that inhibits RANKL and has been on the market for 3 years, and an sclerostin (SOST) antibody has recently completed 5 years of testing and is likely to be approved soon. Although these particular targets were identified before the advent of GWAS, it is possible that genomic approaches will lead to new discoveries in these or other pathways that will prove druggable.

\section{New approaches/future directions}

As for many other complex diseases, the future of genomics research in osteoporosis will almost certainly include a thorough investigation of the role of rare variants discovered by deep sequencing of osteoporosis candidate genes as well as those discovered through a variety of other sources, including exome sequencing and the 1000 Genomes Project. An association study targeted to rare variants will be potentially useful for two reasons. First, because GWAS SNP arrays do not generally tag variants with minor allele frequencies less than 5\% well, direct genotyping of these SNPs is the only way to assess the low frequency spectrum of allelic variation. Second, rare variants located within the exons of genes may include some that disrupt gene function, thus potentially having large effects on phenotype expression. Even if these mutations are rare, their identification can shed important insights into the role of that particular gene (and perhaps gene pathway) in bone biology.

Other approaches for identifying genetic variants associated with BMD and/or fracture risk are in their infancy. Epigenetic factors that do not modify the DNA sequence itself, but rather gene expression, may play important roles. The most well known epigenetic mechanisms are DNA methylation and histone modifications, which act at the level of gene transcription, and miRNAs (microRNAs), which act at the post-transcriptional level. Epigenetic marks may drive differentiation programs for cell fate, including osteoblastic lineage differentiation, and/or may be important regulators of bone remodeling during osteoclastogenesis. ${ }^{73}$ In fact, recent evidence suggests that methylation-dependent mechanisms may influence the transcription of RANKL and OPG expression. ${ }^{74}$ One speculation is that epigenetic marks may be modified by nutritional factors, intrauterine growth influences, and/or other environmental factors, although at the present time it is not clear what these modifying factors are and what are the key epigenetic marks most relevant to osteoporosis. Resolving these questions has been difficult for a number of reasons, including obtaining accurate measurement of the relevant exposures, identifying the relevant epigenetic marks to measure, and the cell and/or tissue specificity of epigenetic marks. These challenges notwithstanding, elucidation of epigenetic control of bone regulation may have translational implications; for example, some demethylating agents are already used to treat neoplastic disorders. ${ }^{75,76}$

There has been very limited research to date into the genetic determinants of response to treatment with antiresorptive agents used to slow bone loss in osteoporosis. With increased knowledge of the molecules and pathways that drive the balance between bone formation and bone resorption, one can imagine that drug treatments could be refined and optimized according to the patient's individual genetic profile to allow the most beneficial treatment for each patient. The degree to which this can be realized is hard to say, because it may depend not only on how individual polymorphisms influence response to treatment, but perhaps also on how combinations of polymorphisms in aggregate influence response.

\section{Conclusion}

Over 60 variants identified over the past 7 years have been reliably associated with variation in BMD, some of which are also associated with fracture risk. Many of these variants map to genes in known pathways that are related to bone biology, although some map to genes with a relation to bone biology that is not readily apparent. A key point is that the effect sizes of variants are very small, because they collectively account for less than $6 \%$ of the variation in BMD. Although predicting individuals at risk for future fracture would be of enormous value so that treatment can be initiated early, the current panel of variants is not useful for prediction of future fracture, given that adding them to prediction models that already include age, gender, and BMD offers only a negligible improvement in predictive value. One hope is that future genetic discoveries made through even larger meta-analyses or new discoveries based on analyses of rare variants will identify new pathways relevant to the pathophysiology of bone metabolism or lead to a more granular characterization of known pathways. Such knowledge could inspire the development of more targeted therapeutics to prevent age-related bone loss.

\section{Acknowledgment}

Partial funding for this project was provided by the MidAtlantic Nutrition and Obesity Research Center (P30 DK072488). 


\section{Disclosure}

The authors report no conflicts of interest in this work.

\section{References}

1. United States Bone and Joint Initiative. The burden of musculoskeletal diseases in the United States. 2011. Available from: http://www. boneandjointburden.org/. Accessed September 4, 2013.

2. Nguyen ND, Ahlborg HG, Center JR, Eisman JA, Nguyen TV. Residual lifetime risk of fractures in women and men. $J$ Bone Miner Res. 2007;22:781-788

3. Burge R, Dawson-Hughes B, Solomon DH, Wong JB, King A, Tosteson A. Incidence and economic burden of osteoporosis-related fractures in the United States, 2005-2025. J Bone Miner Res. 2007;22:465-475.

4. NIH Consensus Development Panel. Osteoporosis prevention, diagnosis, and therapy. JAMA. 2001;285:785-795.

5. Peacock M, Turner CH, Econs MJ, Foroud T. Genetics of osteoporosis. Endocr Rev. 2002;23:303-326.

6. Ng MY, Sham PC, Paterson AD, Chan V, Kung AW. Effect of environmental factors and gender on the heritability of bone mineral density and bone size. Ann Hum Genet. 2006;70:428-438.

7. Chesnut $\mathrm{CH}$ 3rd. Is osteoporosis a pediatric disease? Peak bone mass attainment in the adolescent female. Public Health Rep. 1989; Suppl 104: $50-54$.

8. Watts NB. Clinical utility of biochemical markers of bone remodeling. Clin Chem. 1999;45:1359-1368.

9. Tosteson AN, Gottlieb DJ, Radley DC, Fisher ES, Melton LJ 3rd. Excess mortality following hip fracture: the role of underlying health status. Osteoporos Int. 2007;18:1463-1472.

10. Haentjens P, Magaziner J, Colon-Emeric CS, et al. Meta-analysis: excess mortality after hip fracture among older women and men. Ann Intern Med. 2010;152:380-390.

11. Sterling RS. Gender and race/ethnicity differences in hip fracture incidence, morbidity, mortality, and function. Clin Orthop Relat Res. 2011;469:1913-1918.

12. Pongchaiyakul C, Nguyen ND, Jones G, Center JR, Eisman JA, Nguyen TV. Asymptomatic vertebral deformity as a major risk factor for subsequent fractures and mortality: a long-term prospective study. J Bone Miner Res. 2005;20:1349-1355.

13. Hallberg I, Rosenqvist AM, Kartous L, Löfman O, Wahlström O, Toss G. Health-related quality of life after osteoporotic fractures. Osteoporos Int. 2004;15:834-841.

14. Adachi JD, Adami S, Gehlbach S, et al; GLOW Investigators. Impact of prevalent fractures on quality of life: baseline results from the global longitudinal study of osteoporosis in women. Mayo Clin Proc. 2010;85: 806-813.

15. Solimeo SL, Silverman SL, Calderon AD, Nguyen A, Gold DT. Measuring health-related quality of life (HRQOL) in osteoporotic males using the male OPAQ. Osteoporos Int. 2012;23:841-852.

16. Black DM, Delmas PD, Eastell R, et al; HORIZON Pivotal Fracture Trial. Once-yearly zoledronic acid for treatment of postmenopausal osteoporosis. N Engl J Med. 2007;356:1809-1822.

17. Lyles KW, Colon-Emeric CS, Magaziner JS, et al; HORIZON Recurrent Fracture Trial. Zoledronic acid and clinical fractures and mortality after hip fracture. N Engl J Med. 2007;357:1799-1809.

18. Bono CM, Einhorn TA. Overview of osteoporosis: pathophysiology and determinants of bone strength. Eur Spine J. 2003;12 Suppl 2: S90-S96.

19. Bouxsein ML, Seeman E. Quantifying the material and structural determinants of bone strength. Best Pract Res Clin Rheumatol. 2009;23: 741-753.

20. World Health Organization. Assessment of fracture risk and its application to screening for postmenopausal osteoporosis. Report of a WHO Study Group. World Health Organ Tech Rep Ser. 1994;843:1-129.

21. Martinez-Morillo M, Grados D, Holgado S. Premenopausal osteoporosis: how to treat? Reumatol Clin. 2012;8:93-97.
22. National Osteoporosis Foundation. Clinician's Guide to Prevention and Treatment of Osteoporosis. Washington, DC: National Osteoporosis Foundation; 2008.

23. Marini F, Brandi ML. Pharmacogenetics of osteoporosis: future perspectives. Calcif Tissue Int. 2009;84:337-347.

24. Marini F, Brandi ML. Pharmacogenetics of osteoporosis: what is the evidence? Curr Osteoporos Rep. 2012;10:221-227.

25. Compston J. Clinical and therapeutic aspects of osteoporosis. Eur J Radiol. 2009;71:388-391.

26. King AB, Fiorentino DM. Medicare payment cuts for osteoporosis testing reduced use despite tests' benefit in reducing fractures. Health Aff (Millwood). 2011;30:2362-2370.

27. O'Malley CD, Johnston SS, Lenhart G, Cherkowski G, Palmer L, Morgan SL. Trends in dual-energy x-ray absorptiometry in the United States, 2000-2009. J Clin Densitom. 2011;14:100-107.

28. Tanner SB. Dual-energy x-ray absorptiometry in clinical practice: new guidelines and concerns. Curr Opin Rheumatol. 2011;23:385-388.

29. Marshall D, Johnell O, Wedel H. Meta-analysis of how well measures of bone mineral density predict occurrence of osteoporotic fractures. BMJ. 1996;312:1254-1259.

30. Johnell O, Kanis JA, Oden A, et al. Predictive value of BMD for hip and other fractures. J Bone Miner Res. 2005;20:1185-1194.

31. Jones G, Nguyen T, Sambrook P, Kelly PJ, Eisman JA. Progressive loss of bone in the femoral neck in elderly people: longitudinal findings from the Dubbo osteoporosis epidemiology study. BMJ. 1994;309:691-695.

32. Smith JA, Vento JA, Spencer RP, Tendler BE. Aortic calcification contributing to bone densitometry measurement. J Clin Densitom. 1999;2:181-183.

33. Nguyen ND, Eisman JA, Center JR, Nguyen TV. Risk factors for fracture in nonosteoporotic men and women. J Clin Endocrinol Metab. 2007;92:955-962.

34. Nishiyama KK, Macdonald HM, Hanley DA, Boyd SK. Women with previous fragility fractures can be classified based on bone microarchitecture and finite element analysis measured with HR-pQCT. Osteoporos Int. 2013;24:1733-1740.

35. Dawson-Hughes B, Looker AC, Tosteson AN, Johansson H, Kanis JA, Melton LJ 3rd. The potential impact of the National Osteoporosis Foundation guidance on treatment eligibility in the USA: an update in NHANES 2005-2008. Osteoporos Int. 2012;23:811-820.

36. Samelson EJ, Hannan MT. Epidemiology of osteoporosis. Curr Rheumatol Rep. 2006;8:76-83.

37. Kiel DP, Rosen CJ, Dempster D. Age-Related Bone Loss. Chapter 20. John Wiley \& Sons Inc; 2009.

38. Lane NE. Epidemiology, etiology, and diagnosis of osteoporosis. Am J Obstet Gynecol. 2006;194:S3-S11.

39. Mitchell BD, Kammerer CM, Schneider JL, Perez R, Bauer RL. Genetic and environmental determinants of bone mineral density in Mexican Americans: results from the San Antonio Family Osteoporosis Study. Bone. 2003;33:839-846.

40. Faulkner KG, Wacker WK, Barden HS, et al. Femur strength index predicts hip fracture independent of bone density and hip axis length. Osteoporos Int. 2006;17:593-599.

41. Pulkkinen P, Jämsä T, Lochmüller EM, Kuhn V, Nieminen MT, Eckstein F. Experimental hip fracture load can be predicted from plain radiography by combined analysis of trabecular bone structure and bone geometry. Osteoporos Int. 2008;19:547-558.

42. Michaëlsson K, Melhus H, Ferm H, Ahlbom A, Pedersen NL. Genetic liability to fractures in the elderly. Arch Intern Med. 2005;165: $1825-1830$.

43. Deng HW, Chen WM, Recker S, et al. Genetic determination of Colles' fracture and differential bone mass in women with and without Colles' fracture. J Bone Miner Res. 2000;15:1243-1252.

44. Andrew T, Antioniades L, Scurrah KJ, Macgregor AJ, Spector TD. Risk of wrist fracture in women is heritable and is influenced by genes that are largely independent of those influencing BMD. J Bone Miner Res. 2005;20:67-74. 
45. Seeman E, Hopper JL, Bach LA, et al. Reduced bone mass in daughters of women with osteoporosis. N Engl J Med. 1989;320:554-558.

46. Hui SL, Koller DL, Foroud TM, Econs MJ, Johnston CC, Peacock M. Heritability of changes in bone size and bone mass with age in premenopausal white sisters. J Bone Miner Res. 2006;21:1121-1125.

47. Shaffer JR, Kammerer CM, Dressen AS, Bruder JM, Bauer RL, Mitchell BD. Rate of bone loss is greater in young Mexican American men than women: the San Antonio Family Osteoporosis study. Bone. 2010;47:49-54.

48. Brown LB, Streeten EA, Shapiro JR, et al. Genetic and environmental influences on bone mineral density in pre- and post-menopausal women. Osteoporos Int. 2005;16:1849-1856.

49. Kelly PJ, Nguyen T, Hopper J, Pocock N, Sambrook P, Eisman J. Changes in axial bone density with age: a twin study. $J$ Bone Miner Res. 1993;8:11-17.

50. Christian JC, Yu PL, Slemenda CW, Johnston CC Jr. Heritability of bone mass: a longitudinal study in aging male twins. Am J Hum Genet. 1989:44:429-433.

51. Shaffer JR, Kammerer CM, Bruder J, et al. Five-year change in bone mineral density is heritable in Mexican Americans: The San Antonio Family Osteoporosis Study. J Bone Miner Res. 2005;20 Suppl 1:S67.

52. Makovey J, Nguyen TV, Naganathan V, Wark JD, Sambrook PN Genetic effects on bone loss in peri- and postmenopausal women: a longitudinal twin study. J Bone Miner Res. 2007;22:1773-1780.

53. Mitchell BD, Yerges-Armstrong LM. The genetics of bone loss: challenges and prospects. J Clin Endocrinol Metab. 2011;96:1258-1268.

54. Estrada K, Styrkarsdottir U, Evangelou E, et al. Genome-wide metaanalysis identifies 56 bone mineral density loci and reveals 14 loci associated with risk of fracture. Nat Genet. 2012;44:491-501.

55. Richards JB, Zheng HF, Spector TD. Genetics of osteoporosis from genome-wide association studies: advances and challenges. Nat Rev Genet. 2012;13:576-588.

56. Gong Y, Slee RB, Fukai N, et al; Osteoporosis-Pseudoglioma Syndrome Collaborative Group. LDL receptor-related protein 5 (LRP5) affects bone accrual and eye development. Cell. 2001;107:513-523.

57. Clarke B. Normal bone anatomy and physiology. Clin J Am Soc Nephrol. 2008;3 Suppl 3:S131-S139.

58. Guo Y, Tan LJ, Lei SF, et al. Genome-wide association study identifies ALDH7a1 as a novel susceptibility gene for osteoporosis. PLoS Genet 2010;6:e1000806.

59. Giuliani N, Girasole G, Vescovi PP, Passeri G, Pedrazzoni M. Ethanol and acetaldehyde inhibit the formation of early osteoblast progenitors in murine and human bone marrow cultures. Alcohol Clin Exp Res. 1999;23:381-385.

60. Ralston SH, Uitterlinden AG. Genetics of osteoporosis. Endocr Rev. 2010;31:629-662.
61. Li WF, Hou SX, Yu B, Li MM, Férec C, Chen JM. Genetics of osteoporosis: accelerating pace in gene identification and validation. Hum Genet. 2010;127:249-285.

62. Farber CR, Lusis AJ. Future of osteoporosis genetics: enhancing genomewide association studies. J Bone Miner Res. 2009;24:1937-1942.

63. Duncan EL, Brown MA. Genetic determinants of bone density and fracture risk - state of the art and future directions. J Clin Endocrinol Metab. 2010;95:2576-2587.

64. Hopkins RB, Goeree R, Pullenayegum E, et al. The relative efficacy of nine osteoporosis medications for reducing the rate of fractures in post-menopausal women. BMC Musculoskelet Disord. 2011;12:209.

65. Wainwright SA, Marshall LM, Ensrud KE, et al; Study of Osteoporotic Fractures Research Group. Hip fracture in women without osteoporosis. J Clin Endocrinol Metab. 2005;90:2787-2793.

66. Nguyen ND, Frost SA, Center JR, Eisman JA, Nguyen TV. Development of a nomogram for individualizing hip fracture risk in men and women. Osteoporos Int. 2007;18:1109-1117.

67. Nguyen ND, Frost SA, Center JR, Eisman JA, Nguyen TV. Development of prognostic nomograms for individualizing 5-year and 10-year fracture risks. Osteoporos Int. 2008;19:1431-1444.

68. Tran BN, Nguyen ND, Center JR, Eisman JA, Nguyen TV. Enhancement of absolute fracture risk prognosis with genetic marker: the collagen 1 alpha 1 gene. Calcif Tissue Int. 2009;85:379-388.

69. Nguyen TV, Eisman JA. Genetics and the individualized prediction of fracture. Curr Osteoporos Rep. 2012;10:236-244.

70. Hsu YH, Zillikens MC, Wilson SG, et al. An integration of genomewide association study and gene expression profiling to prioritize the discovery of novel susceptibility loci for osteoporosis-related traits. PLoS Genet. 2010;6:e1000977.

71. Lui JC, Nilsson O, Chan Y, et al. Synthesizing genome-wide association studies and expression microarray reveals novel genes that act in the human growth plate to modulate height. Hum Mol Genet. 2012;21:5193-5201.

72. Bone H. Future directions in osteoporosis therapeutics. Endocrinol Metab Clin North Am. 2012;41:655-661.

73. Delgado-Calle J, Garmilla P, Riancho JA. Do epigenetic marks govern bone mass and homeostasis? Curr Genomics. 2012;13:252-263.

74. Delgado-Calle J, Sañudo C, Fernández AF, García-Renedo R, Fraga MF, Riancho JA. Role of DNA methylation in the regulation of the RANKL-OPG system in human bone. Epigenetics. 2012;7:83-91.

75. La Thangue NB. Histone deacetylase inhibitors and cancer therapy. J Chemother. 2004;16 Suppl 4:64-67.

76. Santos FP, Kantarjian H, Garcia-Manero G, Issa JP, Ravandi F. Decitabine in the treatment of myelodysplastic syndromes. Expert Rev Anticancer Ther. 2010;10:9-22.
The Application of Clinical Genetics

\section{Publish your work in this journal}

The Application of Clinical Genetics is an international, peer-reviewed open access journal that welcomes laboratory and clinical findings in the field of human genetics. Specific topics include: Population genetics; Functional genetics; Natural history of genetic disease; Management of genetic disease; Mechanisms of genetic disease; Counseling and ethical

\section{Dovepress}

issues; Animal models; Pharmacogenetics; Prenatal diagnosis; Dysmorphology. The manuscript management system is completely online and includes a very quick and fair peer-review system, which is all easy to use. Visit http://www.dovepress.com/testimonials.php to read real quotes from published authors 